\title{
Çok Amaçlı Ardışık Baraj Haznelerinin İşletmesinin HEC-ResSim ile Simülasyonu
}

\author{
Seda SEVER ${ }^{1}$ \\ Recep YURTAL ${ }^{2}$
}

\section{ÖZ}

Çok amaçlı ardışık baraj haznelerinin işletilmesinde, sistemin davranışını incelemeye olanak sağlayan simülasyon tekniği uygulamalarda tercih edilmektedir. $\mathrm{Bu}$ çalışmada, genelleştirilmiş simülasyon programı HEC-ResSim kullanılarak Ceyhan Havzası'nda ardışık olarak inşa edilmiş Aslantaş Barajı, Berke Barajı ve Sır Barajı'nda üretilen yıllık toplam enerjiyi eniyilemek amaçlanmıştır. Barajlar, mevcut durumda üretebilecekleri maksimum enerji için belirlenen kurallar doğrultusunda çoklu rezervuar sistem yaklaşımıyla işletilmiştir. Gerçekleştirilen işletme çalışması ile sistemin Ceyhan Master Planı'nda üretilen yıllık toplam enerjiden \%57,87 daha fazla enerji üretebileceği sonucuna ulaşılmıştır.

Anahtar Kelimeler: Çoklu rezervuar sistemi, rezervuar işletmesi, hidroelektrik enerji, simülasyon, HEC-ResSim.

\begin{abstract}
Simulation of Multi-Purpose Multi-Reservoir System Operations by HEC-Ressim

In the operation of multi-purpose multi-reservoir system, simulation technique that allows to examine the behavior of the system is preferred. In this study, it was aimed to optimize the annual total energy generated in Aslantaş Dam, Berke Dam and Sir Dam, which were constructed consecutively in Ceyhan Basin, by using the generalized simulation program (HEC-ResSim). Dams have been operated with a multiple reservoir system approach in line with the rules determined for the maximum energy they can generate at present. With this operation policy, it has been concluded that the system can generate $57.87 \%$ more than the annual total energy produced in the Ceyhan Master Plan.
\end{abstract}

\footnotetext{
Not: Bu yazı

- Yayın Kurulu'na 25 Şubat 2021 günü ulaşmıştır. 29 Kasım 2021 günü yayımlanmak üzere kabul edilmiştir.

- 31 Ocak 2023 gününe kadar tartışmaya açıktır.

- https://doi.org/10.18400/tekderg.886723

1 Çukurova Üniversitesi, İnşaat Mühendisliği Bölümü, Adana ssever@cu.edu.tr - https://orcid.org/0000-0003-1187-2704

2 Çukurova Üniversitesi, İnşaat Mühendisliği Bölümü, Adana ryurtal@cu.edu.tr - https://orcid.org/0000-0003-3175-6567
}

"Bu makale, 2020 yılında yazarın Prof. Dr. Recep YURTAL'ın danışmanlığında tamamladığı Yüksek Lisans tezinden üretilmiştir." 
Keywords: Multi-reservoir system, reservoir operation, hydroelectric energy, simulation, HEC-ResSim

\section{GİRIŞ}

Sanayileşmedeki gelişmeler ve nüfus artışı, enerjiye olan talebin artmasına sebep olmaktadır. $\mathrm{Bu}$ enerji talebinin yerli ve yenilenebilir enerji kaynağı olan hidroelektrik enerjiden karşılanması büyük bir öneme sahiptir. Ancak, küresel 1sınma hidroelektrik enerji kaynaklarını olumsuz yönde etkilemektedir. Bu etkilerin azaltılması, sistemden maksimum faydanın elde edilmesi ancak hidroelektrik enerji kaynaklarının verimli kullanılması ile mümkündür. Hidroelektrik enerji üretiminin yanı sıra su temini, taşkın kontrolü gibi farklı amaçlar için inşa edilen barajların işletilmesi bu konuda önem taşımaktadır.

Doğal mevsimsel farklılıklar ve iklim değişikliğine bağlı olarak giriş akımının değişkenlik göstermesi, rezervuar işletme kurallarının güncel tutulmasını zorunlu kılmaktadır. Su temini ve enerji üretimi için sistem performansını artıran, salıverilecek su için istenmeyen sapmayı en aza indiren işletme kuralları en uygun kurallardır [1]. Bu kuralların belirlenmesinde planlayıcıların deneyimlerini ve değerlendirmelerini modele dahil eden rezervuar simülasyon modelleri [2], tercih edilen yaygın bir tekniktir [3]. Simülasyon yöntemlerinin su kaynakları planlaması ve yönetimine uygulanması, ABD Ordusu Mühendisler Birliği'nin (USACE) Missouri Nehri'nin simülasyonunu yapması ile başlamıştır. Sonrasında Nil Havzası'ndaki rezervuarların ekonomik performanslarıyla ilgili simülasyon çalışması yapılmıştır [4].

Her havza farklı topografik ve hidrolojik özelliklere sahip olduğu için araştırmacılar her bir havzaya özgü simülasyon yöntemi uygulamak yerine genelleştirilmiş simülasyon modellerini kullanmayı tercih edebilmektedir. Babel vd. [5], çevresel akış ve hidroelektrik enerji ihtiyaçlarının karşılanması için işletme kurallarının belirlenmesinde simülasyon tekniğinden faydalanmışlardır. Choo vd. [6], taşkın kontrolü ve hidroelektrik enerji üretimi için inşa edilmesini önerdikleri barajın planlamasını genelleştirilmiş simülasyon programı (HECResSim) ile doğrulamışlardır. Shrestha vd. [7], yaptıkları yağış tahminlerine bağlı olarak nehir akışındaki değişimin hidroelektrik enerji üretimi üzerindeki etkisini belirlemek maksadıyla yağışlı ve kurak dönemlerde farklı çalışma saatleri için simülasyon çalışması gerçekleştirmişlerdir. Firoz vd [8], hidrolojik kuraklığın su temini, hidroelektrik enerji üretimi ve tarımsal üretim üzerindeki etkisini belirlemek amacıyla simülasyon çalışması yapmışlardır ve HEC-ResSim'den faydalanmışlardır. Uysal vd. [9], Yuvacık Barajı'nın mevcut işletme kurallarını değerlendirmek ve yeniden düzenlemek için hidrolojik modelleme sistemi (HEC-HMS) ve rezervuar simülasyon modelinin (HEC-ResSim) kombinasyonuyla bir karar destek sistemi geliştirmişlerdir. Özbakır [10], Seyhan ve Ceyhan Havzalarının su potansiyelini incelemek için mevcut ve planlanan projeleri dikkate alarak alternatif işletme politikaları belirlemiştir. Seyhan Havzası'nda depolanamayan Akdeniz'e dökülen suların Ceyhan Havzası'na aktarılmasını önermiş ve bu durumu incelemiştir. Akbulut [11], Ceyhan Havzası için HEC-5 programıyla işletme kuralları belirlemiş ve Aslantaş Barajı'nın enerji üretim kapasitesini değerlendirmiştir. Sever [12], Ceyhan Havzası'nda bulunan Aslantaş Barajı, Berke Barajı ve Sır Barajı'nı bir sistem olarak ele almış ve bu sistemin ürettiği yıllık toplam enerjiyi maksimize etmek için genelleştirilmiş simülasyon programı (HEC-ResSim) kullanarak işletme çalışması yapmıştır. 
Bu çalışmanın amacı, Ceyhan Havzası'nda ardışık inşa edilmiş Aslantaş Barajı, Berke Barajı ve Sır Barajı'nda üretilen yıllık toplam enerjinin eniyilenmesidir. Aslantaş Barajı enerji, sulama ve taşkın amaçlı, Berke Barajı ve Sır Barajı ise enerji amaçlı işletilmektedir. Genelleştirilmiş simülasyon programı HEC-ResSim kullanılarak çoklu rezervuar sistem yaklaşımı ile işletme çalışması yapılmıştır. Barajların hali hazırdaki durumları için işletme kuralları belirlenmiştir.

\section{2. ÇALIŞMA ALANI}

Ceyhan Nehri'nin Ceyhan Havzası, $36^{\circ} 55^{\prime}$ ile $38^{\circ} 72^{\prime}$ kuzey enlemleri $35^{\circ} 45^{\prime}$ ile $37^{\circ} 81^{\prime}$ doğu boylamları arasında Türkiye'nin Doğu Akdeniz Bölgesi'nde bulunmaktadır. $21391 \mathrm{~km}^{2}$ 'lik yüz ölçümüne sahip Ceyhan Havzası batıda Seyhan, kuzeyde ve doğuda Frrat, güneyde Asi ve Fırat havzaları ile sınırlanmıştır. Yer şekilleri ve iklim özellikleri bakımından Yukarı Ceyhan, Orta Ceyhan ve Aşağı Ceyhan olmak üzere üç alt havzaya ayrılmıştır. Yukarı Ceyhan Havzası'nda karasal iklim, Orta Ceyhan Havzası'nda karasal iklim ile akdeniz iklimi arasında geçiş iklimi, Aşağı Ceyhan Havzası'nda akdeniz iklimi hakimdir. Elbistan ilçe merkezinin $3 \mathrm{~km}$ doğusunda Pınarbaşı Mevkii'nde karstik kaynaklardan doğan Ceyhan Nehri, 509 km uzunluğa sahiptir [13]. Ana ve tali kolları üzerinde sulama, içme-kullanma suyu temini, taşkın kontrolü, hidroelektrik enerji üretimi, havzalar arası su aktarma gibi farklı amaçlar için inşa edilen barajlar mevcuttur. Aslantaş Barajı, Berke Barajı ve Sır Barajı ana kol üzerinde ardışık olarak inşa edilmiştir. Ardışık barajların boykesiti Şekil 1'de verilmiştir [13].

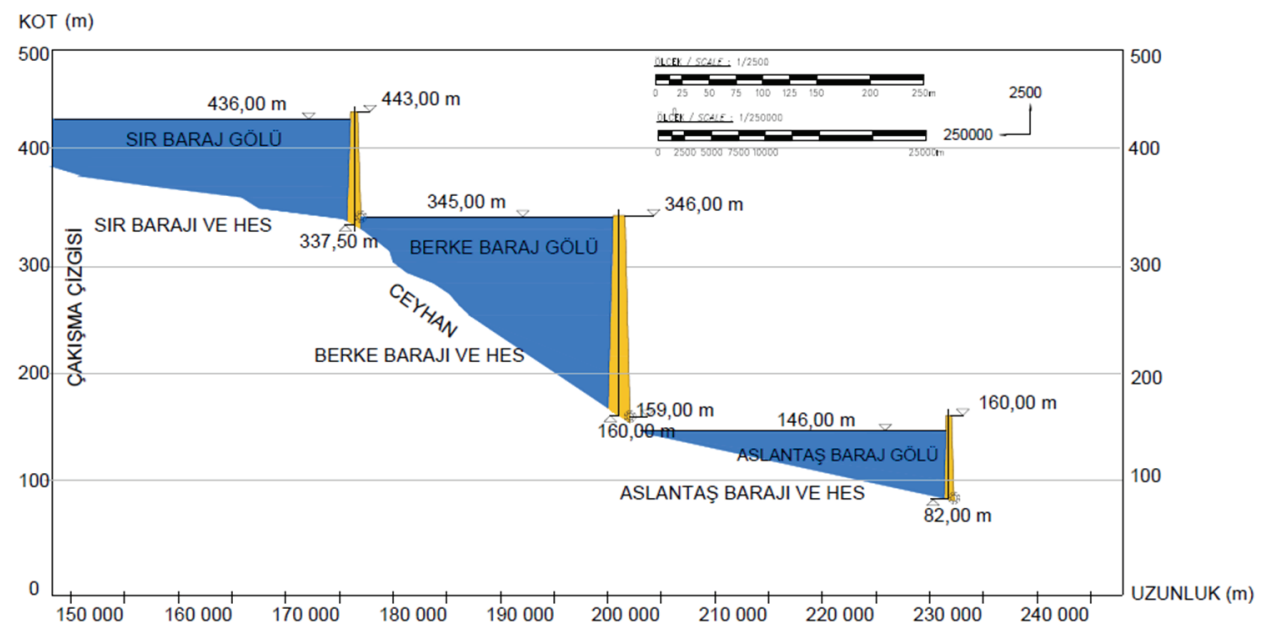

Şekil 1- Simülasyon çalışması yapılan ardışık barajların boykesiti

Aslantaş Barajı, Aşağı Ceyhan Havzası'nda, Osmaniye ilinde yer almaktadır. Kil çekirdekli zonlu toprak dolgu baraj olarak inşa edilmiştir. Su temini, taşkın kontrolü ve enerji amaçlı olarak 1984 yılında işletmeye açılmıştır. $14874 \mathrm{~km}^{2}$ 'lik yağış alanına sahiptir. Ortalama doğal akımı 5604 hm³/yıl’dır. Berke Barajı, Aşağı Ceyhan Havzası'nda, Osmaniye ilinde yer 
almaktadır. Aslantaş Barajı'nın membasında, çift eğrili ince kemer baraj olarak inşa edilmiştir. Enerji amaçlı olarak 2002 yılında işletmeye açılmıştır. $13500 \mathrm{~km}^{2}$ ’lik yağış alanına sahiptir. Ortalama doğal akımı $4511 \mathrm{hm}^{3} /$ yıl'dır. Sır Barajı, Orta Ceyhan Havzası'nda, Kahramanmaraş ilinde yer almaktadır. Berke Barajı'nın membasında beton kemer baraj tipinde inşa edilmiştir. Enerji amaçlı olarak 1991 yılında işletmeye açılmıştır. Ortalama doğal akımı $424 \mathrm{hm}^{3} /$ yıl'dır. Barajlara ait teknik karakteristik bilgiler Tablo 1'de verilmiştir [13].

Tablo 1-Çalışmada kullanılan barajların teknik karakteristik özellikleri

\begin{tabular}{|c|c|c|c|}
\hline & $\begin{array}{l}\text { Aslantaş } \\
\text { Barajı }\end{array}$ & $\begin{array}{l}\text { Berke } \\
\text { Barajı }\end{array}$ & $\begin{array}{l}\text { Sir } \\
\text { Barajı }\end{array}$ \\
\hline Maksimum su kotu (m) & 155 & 345 & 440 \\
\hline Normal işletme kotu (m) & 146 & 345 & 436 \\
\hline Minimum su kotu (m) & 130 & 290 & 417,50 \\
\hline Kret kotu (m) & 160 & 346 & 443 \\
\hline Kret uzunluğu (m) & 566 & 270 & 327 \\
\hline \multirow[t]{2}{*}{ Dolusavak tipi } & $\begin{array}{l}\text { Karşıdan alışlı, } \\
\text { radyal kapaklı }\end{array}$ & $\begin{array}{l}\text { 1)Tünel } \\
\text { dolusavak }\end{array}$ & $\begin{array}{l}\text { Gövdeye } \\
\text { bitişik, }\end{array}$ \\
\hline & & $\begin{array}{l}\text { 2)Gövde yüzey } \\
\text { dolusavak }\end{array}$ & $\begin{array}{l}\text { radyal } \\
\text { kapakl1 }\end{array}$ \\
\hline Dolusavak eşik kotu (m) & 139 & $290-337,50$ & 423 \\
\hline Dolusavak kapak sayısı (adet) & 6 & $2-4$ & 3 \\
\hline Dolusavak deşarj kapasitesi $\left(\mathrm{m}^{3} / \mathrm{s}\right)$ & 13800 & $2755^{*} 2-500 * 4$ & 7646 \\
\hline Kurulu güç (MW) & 138 & 514,50 & 261 \\
\hline Kuyruk suyu kotu (m) & 84,15 & 159 & 346,72 \\
\hline Ünite sayısı (adet) & 3 & 3 & 3 \\
\hline Net düşü (m) & 62 & 186,31 & 89,28 \\
\hline $\mathrm{Q}_{\text {proje }}\left(\mathrm{m}^{3} / \mathrm{s}\right)$ & 270 & 100 & 114,25 \\
\hline $\begin{array}{l}\text { Üretilen güvenilir (firm) enerji } \\
(\mathrm{GWh} / \mathrm{y} 1 \mathrm{l})\end{array}$ & 320 & 921 & 408,4 \\
\hline $\begin{array}{l}\text { Üretilen ikincil (sekonder) enerji } \\
(\mathrm{GWh} / \mathrm{y} 1 \mathrm{l})\end{array}$ & 249 & 748 & 316,5 \\
\hline Üretilen toplam enerji (GWh/yıl) & 569 & 1669 & 724,9 \\
\hline
\end{tabular}

\section{METOT}

Barajlar taşkın kontrolü, su temini, hidroelektrik enerji üretimi gibi birden fazla amaca hizmet edecek şekilde ardışık olarak inşa edilebilirler. Çok amaçlı ardışık barajların her bir amaca 
uygun şekilde işletilmesi, her amaca uygun kısıtlamayı beraberinde getirir. Bu kısıtlamaları karşılayacak doğrultuda işletme kurallarının belirlenmesini kolaylaştırmak maksadıyla rezervuar simülasyon modelleri geliştirilmiştir [3]. Rezervuar simülasyon modeli, rezervuarların özelliklerini matematiksel olarak ifade eden [2], her bir ardışık zaman aralığında, belirlenen alternatifler doğrultusunda sistemin davranışını tahmin etmeye olanak sağlayan tekniktir [14]. Rezervuar simülasyon modeli, bir rezervuarın giriş akımları ile çıkış akımları arasındaki su denge denklemine bağlı olarak tahminlerde bulunur.

Bir barajın $t$ anında işletilmesine dair su denge denklemi Eş. 1'deki gibi ifade edilir:

$S_{t}=S_{t-1}+I_{t}-R_{t}-Q_{t}-B_{t}$

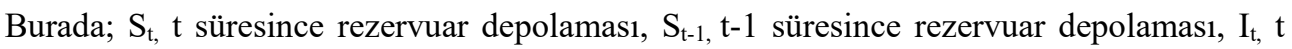
süresince rezervuar giriş akımı, $R_{t}, t$ süresince rezervuar çıkış (dolusavak + su temini) akımı, $\mathrm{Q}_{\mathrm{t}}, \mathrm{t}$ süresince enerji üretimi için salıverilen su miktarı, $\mathrm{B}_{\mathrm{t}, \mathrm{t}} \mathrm{t}$ süresince buharlaşma miktarıdır.

$\mathrm{Bu}$ çalışmada, çok amaçlı çoklu rezervuar sisteminin işletilmesinde genelleştirilmiş simülasyon programı HEC-ResSim kullanılmıştır.

\subsection{HEC-ResSim Modeli}

HEC-ResSim, ABD Ordusu Mühendisliği Birliği tarafından geliştirilen, çoklu rezervuar sistemlerinin değerlendirilmesine olanak sağlayan genelleştirilmiş rezervuar simülasyon programıdır. Program, rezervuar operatörlerinin enerji üretimi, taşkın yönetimi ve çevresel akış için belirlediği kurallar altında sistemin davranışını belirler. Model, bir rezervuar akımını etkileyebilecek hidrolojik koşulları, sistemde bulunan diğer rezervuarların eş zamanlı işletilmesi gibi parametreleri içerir [15]. HEC-ResSim, havza kurulum modülü, rezervuar ağ modülü ve simülasyon modülü olmak üzere modül adı verilen üç işlev kümesine ayrılmıştır. Havza kurulum modülünde nehir güzergahı çizilir ve havzanın fiziksel düzenlemesi yapılır. Rezervuar ağ modülünde havzada bulunan yapıların fiziksel bileşenleri, işletme kuralları ve analiz edilecek alternatifler tanımlanır. Simülasyon ağ modülünde simülasyon zaman aralıkları ve simülasyonun yapılacağı alternatif seçilip, simülasyon başlatılır.

Programın karar verme mantığı, hedef yükseklik olarak kullanıcı tarafından tanımlanan kılavuz eğrisine dayanmaktadır. Tanımlanan işletme kurallarına bağlı olarak hedeflenen kılavuz eğrisini ya da hedeflenen kılavuz eğrisine en yakın eğriyi uygulayarak simülasyon yapmaktadır [16]. HEC-ResSim modeli, her bir rezervuarın işletilmesi esnasında rezervuar seviyesinin bulunduğu zondaki kuralı öncelik sırasına göre kullanır.

Bu çalışmada Aslantaş Barajı, Berke Barajı ve Sır Barajı dahil olmak üzere mevcut bir sistemin simülasyon modeli oluşturulmuştur. Simülasyon çalışması, Tablo 1'de verilen teknik karakteristik özellikler, 1970-2012 yılları arasındaki doğal akım değerleri, barajların işletme amaçları dikkate alınarak günlük zaman aralığında gerçekleştirilmiştir. Program, simülasyon süresinin her bir zaman aralı̆̆ında giriş verisine ihtiyaç duyar. Bu çalı̧̧mada, sistemin girdisi iki rezervuar arasındaki ara havza doğal akımı ile membadaki barajın çıkış akımlarıdır. Bu nedenle, giriş akımlarının ve çıkış akımlarının deşarj edildiği noktalar belirlenmiştir (Şekil 2). Su temin değerleri Ceyhan Master Planı'ndan alınmıştır. Su temin değerleri hesaplanırken Aslantaş Barajı için E20A20 Akım Gözlem İstasyonu (AGI), Berke 
Barajı ve Sır Baraj1 için E20A001, E20A010 ve E20A020 AGI'lerinde ölçülen akım değerlerinden yararlanılmıştır [13]. 1970-2012 yıllarına ait akım verileri kullanılmıştır. Barajın işletilmesi esnasında giriş akımı ve çıkış akımı arasındaki su dengesine bağlı olarak depolama kapasitesinin belirlenmesi için kot-alan-hacim eğrisi tanımlanmıştır. Sadece buharlaşmadan kaynaklı su kaybı dikkate alınmıştır, sızma kayıpları ihmal edilmiştir.

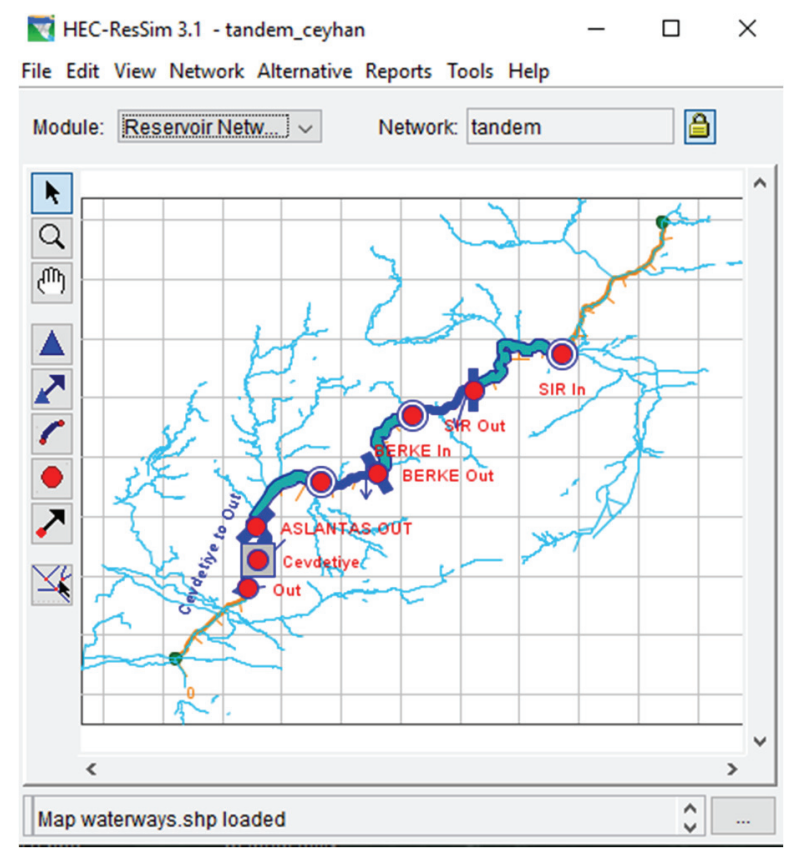

Şekil 2-Mevcut sistemin HEC-ResSim Modeli

Bu çalışmada, barajlar ölü hacim, aktif hacim ve taşkın kontrol hacmi olmak üzere üç zona ayrılmış ve aktif hacim kılavuz eğrisi olarak tanımlanmıştır. Ceyhan Master Planı ile karşılaştırma yapılabilmesi için Kılavuz Eğrileri Ceyhan Master Planı'nda olduğu gibi Aslantaş Barajı için Kasım-Nisan ayları arası 143 m, Mayıs-Ekim ayları arası 153 m, Berke Barajı için sabit 344 m, Sır Barajı için sabit 438 m olarak belirlenmiştir. Barajların zonlarına işletme amaçları göz önünde bulundurularak kurallar tanımlanmış ve önem derecelerine göre sıralanmıştır. Çevresel akışın devamlılığını sağlamak için salıverilmesi gereken minimum su kuralı, üç baraj için en öncelikli kural olarak uygulanmıştır. Bu kural, 2003-2012 yılları arası doğal akımların ortalamasının \%10’u alınarak belirlenmiştir. Çevresel akış kuralından sonra, barajın işletme amacına göre su temini, hidroelektrik enerji üretimi, dolusavak deşarjı ile ilgili kurallar sıralanmıştır. Ancak, önemli bir kuralı kısıtlayan herhangi bir kısıtlayıcı kuralın varlığında bu kısıtlayıcı kurala öncelik verilmiştir. Berke ve Sır Barajı enerji amaçlı işletildikleri için bu barajlara çevresel akış kuralı, hidroelektrik enerji üretimi için kurallar ve olası taşkın anında suyun salıverilmesi için dolusavak deşarjı ile ilgili kurallar tanımlanmıştır. Aslantaş Barajı'nın Cevdetiye Regülatörü'ne su temin etme amacı olduğu için Cevdetiye Regülatörü için akış aşağı aylık su gereksinim kuralı tanımlanmıştır. 
Hidroelektrik enerji kuralı tanımlanırken 2018 yılında üretilen enerji dikkate alınmış ve aylık enerji üretimi MWh talep edilmiştir. Türbinlerden salıverilebilecek suyun maksimum fiziksel kapasiteyi aşmaması önemli olduğundan, türbinlerden salıverilecek maksimum su için sınırlama kuralı belirlenmiştir. Türbinlerden salıverilecek minimum su kısıt olarak tanımlanmıştır. Ayrıca, barajların fiziksel karakteristikleri tanımlanırken enerji üretimi için tasarım debisinin her cebri boruda eşit dağıtıldığı, hidrolik kayıpların her baraj için sabit 1 m, jeneratör veriminin \%97 olduğu kabul edilmiştir.

Dolusavak deşarjı ile ilgili kural tanımlanırken barajların geçmiş yıllardaki gözlenen giriş akımları dikkate alınmıştır. Eğer rezervuar su seviyesi taşkın kontrol hacminde bulunmuyorsa, giriş akımına bağlı olarak Aslantaş Barajı için Kasım-Mayıs, Berke Barajı için Nisan-Mayıs, Sır Barajı için Ocak-Mayıs ayları arasında dolusavaktan suyun salıverilmesine izin verilmiştir. Bu zaman aralıkları geçmiş yıllarda savaklanan akım değerlerinin yine aynı zaman aralıklarında tekrarlanacağı düşünülerek gözlenen akım verilerinin analizi sonucunda belirlenmiştir. Ancak, rezervuar su seviyesi taşkın kontrol hacminde bulunuyorsa on iki ay boyunca dolusavaktan su salıverilmesine izin verilmiş ve olası taşkın ihtimali düşünülerek maksimum deşarj kapasiteleri sınır olarak belirlenmiştir.

\section{SONUÇLAR VE TARTIŞMALAR}

Bu simülasyon çalışmasında Aslantaş Barajı, Berke Barajı ve Sır Barajı'nın ürettikleri yıllık toplam enerjiyi maksimize etmek amaçlanmıştır. HEC-ResSim ile yapılan simülasyon sonuçları ile Ceyhan Master Plan sonuçları kıyaslanmıştır (Tablo 2).

Tablo 2-Ceyhan Master Planı ve HEC-ResSim ile simülasyon sonucunda üretilen yıllık toplam enerji $(G W h)$

\begin{tabular}{llll}
\hline & Ceyhan Master Planı & $\begin{array}{l}\text { HEC-ResSim ile simülasyon } \\
\text { sonucu }\end{array}$ \\
\hline Aslantaş Barajı & 674 & 1150,44 & \\
Berke Baraj1 & 1730,9 & 3084,07 & \\
Sir Baraj1 & 812,6 & 842,70 & \\
\hline
\end{tabular}

Aslantaş Barajı'nda üretilen yıllık enerjiyi maksimum seviyede tutmak için Kılavuz Eğrisi Kasım-Nisan ayları arası $143 \mathrm{~m}$, Mayıs-Ekim ayları arası $153 \mathrm{~m}$ olarak belirlenmiştir. Çalışmanın temel amacı üretilen yıllık toplam enerjiyi maksimum seviyede tutmak olsa da Aslantaş Barajı çok amaçlı işletilmekte olduğu için diğer işletme amaçları da değerlendirilmiştir. Simülasyon sonucunda Aslantaş Barajı, çevresel akış ve Cevdetiye Regülatörü için gerekli olan akış aşağı su ihtiyacını karşılayabilmiştir. Ayrıca taşkın riskine rastlanmamıştır (Şekil 3). 


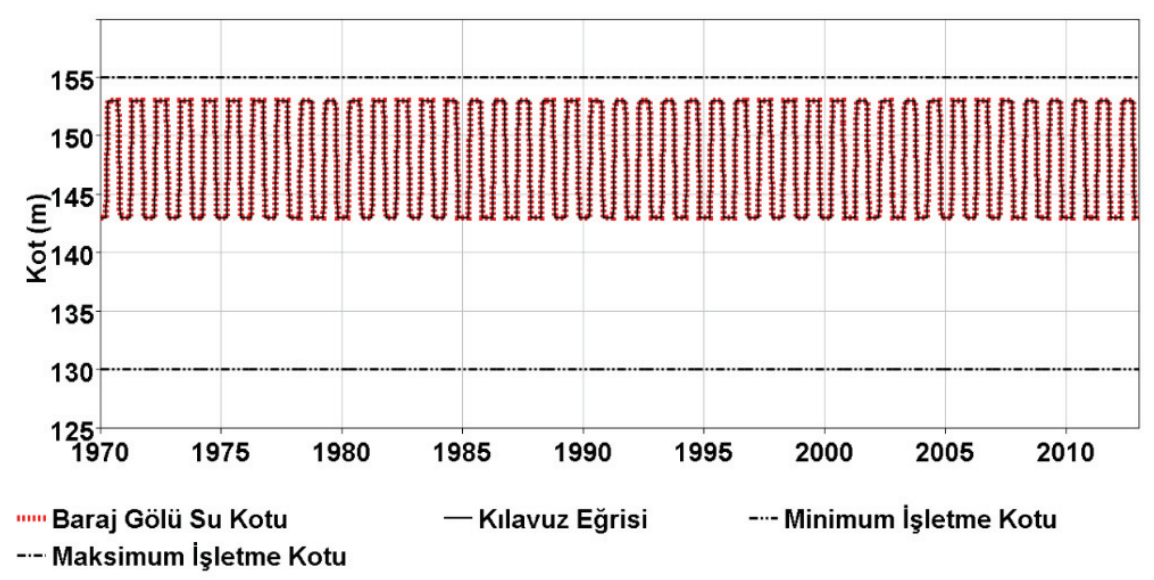

Şekil 3- Simülasyon sonucunda Aslantaş Barajı Kılavuz Ĕ̆risi

Aslantaş Baraj gölünde depolanan suyun tünel ve cebri boru ile $83 \mathrm{~m}$ kotuna düşürülmesiyle enerji üretilmiştir. Yılık toplam 1150,44 $\mathrm{GWh}$ enerji üretebildiği sonucuna ulaşılmıştır (Tablo 2.). Ceyhan Master Planı raporuna göre Aslantaş Barajı'nın bir yılda toplam 674 GWh enerji üretmesi beklenmektedir. Bu iki sonuç kıyaslandığında Aslantaş Barajı'nın ürettiği yıllık toplam enerjide artış görülmektedir. Şekil 4'de simülasyon sonucunda üretilen gücün, kullanıcı tarafindan belirlenen tahmini talep edilen güçten daha fazla olduğu görülmektedir. Aslantaş Baraj1, 321,21 GWh/yıl güvenilir enerji ve 829,23 GWh/yıl ikincil enerji üretmiştir. Aslantaş Barajı, 43 yıllık zaman aralığında talep edilen minimum enerjiyi sağlamış ve Nisan 2007'de minimum enerji üretmiştir (Şekil 4).

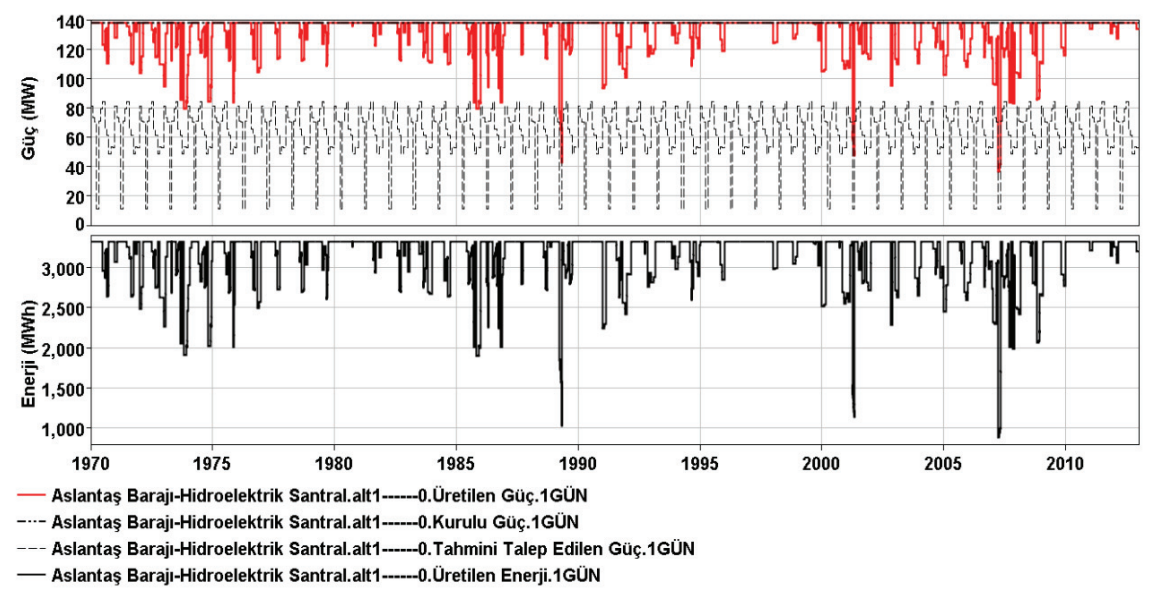

Şekil 4- Simülasyon sonucunda Aslantaş Barajı'nın ürettiği güç ve enerji 
Enerji amaçlı işletilmekte olan Berke Barajı için Kılavuz Eğrisi on iki ay boyunca sabit 344 $\mathrm{m}$ belirlenmiştir. Simülasyon sonucunda barajın yıllık toplam 3084,07 GWh enerji ürettiği Tablo 2'de verilmiştir. Berke Baraj1, 688,92 GWh/yıl güvenilir enerji ve 2393,55 GWh/yıl ikincil enerji üretmiştir. İşletme çalışmasında Berke Barajı'nda üretilen yıllık toplam enerji için maksimum seviyeye ulaşılmış ancak kurak dönemlerde talep edilen minimum enerjinin istenilen seviyede olmadığı sonucuna varılmıştır (Şekil 5). Simülasyon çalışması boyunca en düşük aylık toplam enerji üretimi Eylül 2007 tarihinde 89,18 GWh olarak gözlenmiştir (Şekil 5). Şekil 6'da görüldüğü gibi kurak dönemlerde barajda depolanan su minimum işletme kotuna düşmüştür ancak çevresel akış için gerekli suyu sağlamıştır.

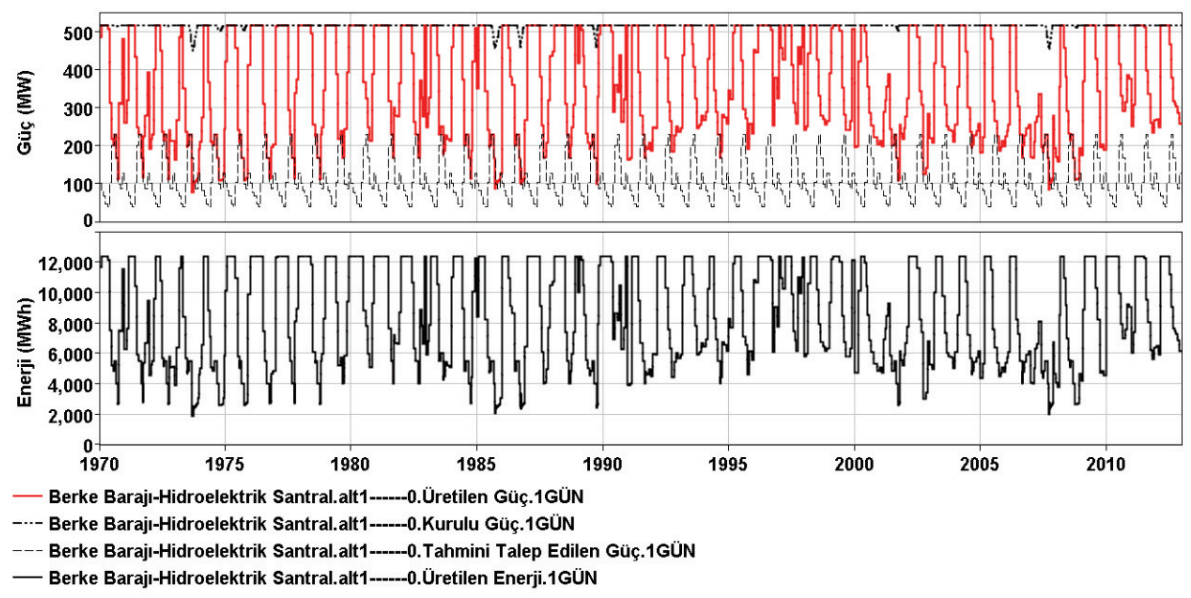

Şekil 5- Simülasyon sonucunda Berke Barajı'nın ürettiği güç ve enerji

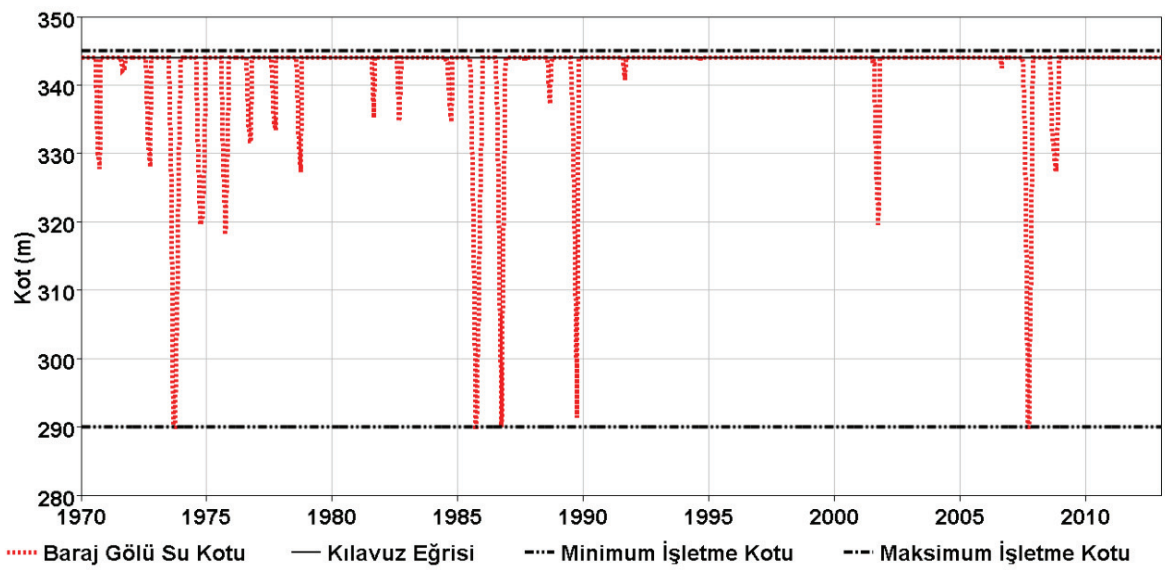

Şekil 6- Simülasyon sonucunda Berke Barajı Kılavuz Ĕgrisi 
Sır Barajı için kılavuz eğrisi on iki ay boyunca sabit $438 \mathrm{~m}$ belirlenmiştir. Tablo 2'de verilen değerler karşılaştırıldığında Sır Barajı 842,70 GWh enerji üreterek Ceyhan Master Planı sonuçlarına göre daha fazla enerji üretmiştir. 160,89 $\mathrm{GWh} / \mathrm{y}$ 1l güvenilir enerji, 681,80 GWh/yıl ikincil enerji üretmiştir. 43 yıllık zaman periyodunda genellikle Temmuz, Ağustos ve Eylül aylarında üretilmesi talep edilen minimum enerjiye ulaşılamamıştır (Şekil 7). Kullanıcı tarafından belirlenen kılavuz eğrisini uygulamış, çevresel akış için su yetersizliğine rastlanmamıştır (Şekil 8).

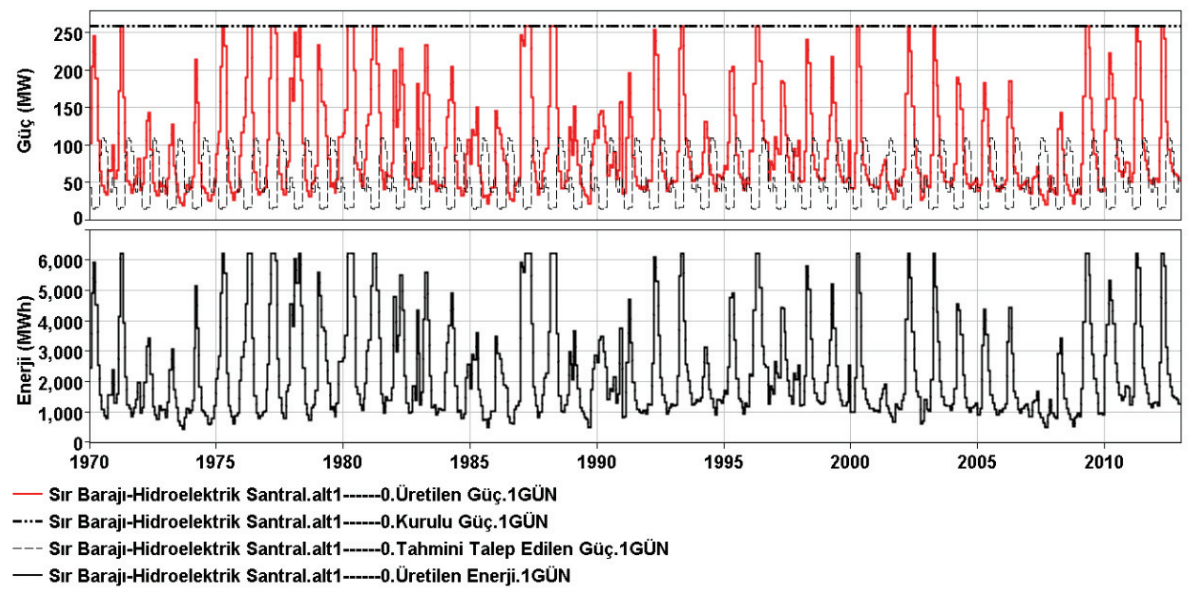

Şekil 7- Simülasyon sonucunda Sır Barajı'nın ürettiği güç ve enerji

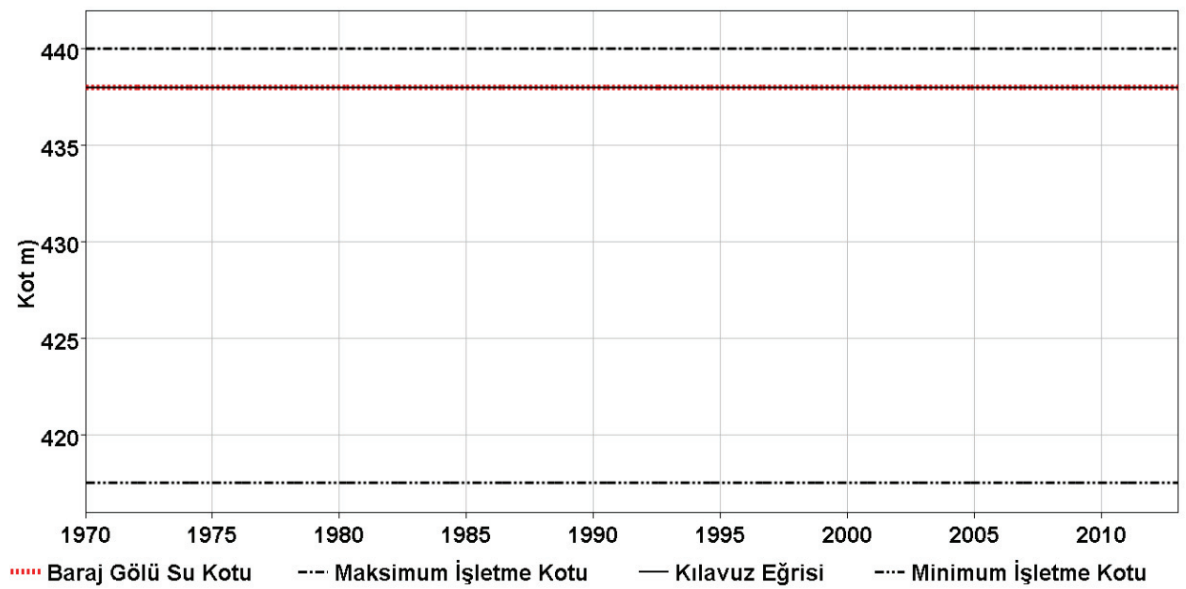

Şekil 8- Simülasyon sonucunda Sır Barajı Kılavuz Ĕ̆risi 


\section{SONUÇLAR}

Ardışık inşa edilen barajlar nehirdeki akım rejimini düzenli hale getirmekte ve her baraj kendisinden bir sonraki baraj için giriş akımı sağlamaktadır. Bu nedenle ardışık barajların bir sistem olarak değerlendirilmesinin gerekli olduğu söylenebilir. Bu çalışmada, Aslantaş Barajı, Berke Barajı ve Sır Barajı bütüncül bir yaklaşımla bir sistem olarak işletilmiş, yıllık toplam üretebilecekleri enerji maksimize edilmiş ve Ceyhan Master Planı sonuçları ile kıyaslanmıştır.

$\mathrm{Bu}$ üç baraj bir sistem olarak değerlendirildiğinde Ceyhan Master Planı sonuçları ile kıyaslandığında toplamda \%57,87 daha fazla enerji üretmiştir. Üretilen toplam enerjideki bu artış, çalışmada sadece üç barajın ele alınması ve bu üç barajın bütünleşik olarak ürettiği yıllık toplam enerjiyi maksimize edecek işletme kurallarının uygulanmış olmasıyla açıklanabilir. Ayrıca, bu çalışmada Berke Barajı'nın beş defa minimum hazne kotuna düşmesine izin verilmiştir. Bu durumun da Ceyhan Master Planı sonuçları ile bu çalışma arasındaki farka sebep olabileceği düşünülmektedir. Barajlarda üretilen enerjideki artış incelendiğinde Aslantaş Barajı ve Berke Barajı'nda üretilen enerjideki artışın, Sır Barajı'nda üretilen enerjideki artıştan daha fazla olduğu sonucuna ulaşılmaktadır. Bu durumun nedeni Aslantaş Barajı ile Berke Barajı'nın daha mansapta bulunması ve bu barajlara gelen akımın kendilerinden önceki baraj tarafından düzenlenmesi ile ilişkilendirilebilir. Çalışmanın amacı üç barajın birlikte yıllık toplam enerjisini maksimize etmek olduğu için güvenilir enerji için alt sınır tanımlanmamıştır. Bu sebeple, Berke ve Sır Barajlarında üretilen güvenilir enerji Master Planı sonucuna göre düşük, Aslantaş Barajı'nda üretilen güvenilir enerji ise bir miktar yüksek çıkmıştır.

Çalışmada oluşturulan model farklı amaçlar için de kullanılabilecek şekilde esnektir ve her türlü alternatif çalışmalar için hazırdır. Çalışmada oluşturulan model ile mevcut verilerle sistemin toplam enerjisi eniyilenmiştir. Ancak model, sonraki yıllar için farklı veri ve talep senaryoları girilerek, ileriye dönük sonuçlar almak için de uygundur. Buradan da modelin ileriye dönük iklim değişikliği senaryoları için rahatlıkla kullanılabileceği söylenebilir.

\section{Semboller}

$\begin{array}{ll}\text { AGI } & : \text { Akım Gözlem İstasyonu } \\ \mathrm{B}_{\mathrm{t}} & : \text { t sürede buharlaşma miktarı } \\ \text { HEC-ResSim } & \text { : Reservoir System Simulation } \\ \text { HES } & : \text { Hidroelektrik Santral } \\ \mathrm{I}_{\mathrm{t}} & : \text { t sürede rezervuar giriş akımı } \\ \mathrm{R}_{\mathrm{t}} & : \text { t sürede rezervuar çıkış (dolusavak + su temini) akımı } \\ \mathrm{S}_{\mathrm{t}} & : \text { t süre sonundaki rezervuar depolaması } \\ \mathrm{S}_{\mathrm{t}-1} & : \text { t-1 süre sonundaki rezervuar depolaması } \\ \mathrm{Q}_{\mathrm{t}} & : \mathrm{t} \text { sürede enerji üretimi için salıverilen su miktarı }\end{array}$




\section{Teşekkür}

Bu çalışma, Çukurova Üniversitesi Bilimsel Araştırma Projeleri Koordinasyon Birimi (Proje No: FYL-2019-12041) tarafından desteklenmiştir.

\section{Kaynaklar}

[1] Ostadrahimi L., Mariño M. A., Afshar A., Multi-reservoir Operation Rules: Multi swarm PSO-based Optimization Approach, Water Resour Manage, 26, 407-427, 2011.

[2] Yeh W. W-G., Reservoir Management and Operations Models: A State-of-the-Art Review, Water Resources Research, 21 (12), 1797-1818, 1985.

[3] Wurbs R. A., Comparative Evaluation of Generalized River/Resorvoir System Models, Technical Report No. 282, Texas Water Resources Institute the Texas A\&M University System College Station, Texas, 2005.

[4] Emergy D. A., and Meek B. I., The Simulation of a Complex River System, in Les Choix Exonomiques, Dunod, Paris, 1960.

[5] Babel M. S., Dinh C. N., Mullick Md. R. A., and Nanduri U. V., Operation of A Hydropower System Considering Environmental Flow Requirements: A Case Study in La Nga River Basin, Vietnam, Journal of Hydro-environment Research, 6, 63-73, 2012.

[6] Choo T. H., Huh, J. Y., Yoon H. C., Yun G. S., and Son J. K, Method for New Conceptual Securing Water Resources: A Case Study of the Miryang Multipurpose Dam in Korea, Environmental Earth Sciences, 75, 857, 2016.

[7] Shrestha S., Khatiwada M., Babel M. S., and Parajuli K., Impact of Climate Change on River Flow and Hydropower Production in Kulekhani, Hydropower Project of Nepal. Environmental Processes, 1, 231-250, 2014.

[8] Firoz A. B. M., Nauditt A., Fink M., and Ribbe L., Quantifying Human Impacts on Hydrological Drought Using A Combined Modeling Approach in A Tropical River Basin in Central Vietnam, Hydrology and System Sciences, 22, 547-565, 2018.

[9] Uysal G., Şensoy A., Şorman A. A., Akgün T., Gezgin T, Basin/Reservoir System Integration for Real Time Reservoir Operation, Water Resour Manage, 30, 1653-1668, 2016.

[10] Özbakır B.,Seyhan ve Ceyhan Nehir Havzalarının Hec-ResSim Programı ile Modellenmesi, Yüksek Lisans Tezi, Gazi Üniversitesi, Fen Bilimleri Enstitüsü, Ankara, 136s, 2009.

[11] Akbulut U., Çok Amaçlı Baraj İşletme Çalışmaları ve Ceyhan Havzasının HEC-5 Simülasyon Programı ile Modellenmesi. Yüksek Lisans Tezi, Gazi Üniversitesi, Fen Bilimleri Enstirüsü, Ankara, 2003.

[12] Sever S., Çok Amaçlı Ardışık Baraj Haznelerinin İşletmesinin HEC-ResSim ile Simülasyonu, Yüksek Lisans Tezi, Çukurova Üniversitesi, Fen Bilimleri Enstitüsü, Adana, 2020. 
[13] DSİ Genel Müdürlüğ̈̈, Ceyhan Master Planı, Türkiye, 2016.

[14] Wurbs R. A., Reservoir-System Simulation and Optimization Models, Journal of Water Resources Planning and Management, 119 (4), 455-472, 1993.

[15] Seyoum T., and Theobald S., Modeling of Cascade Dams and Reservoirs Operation for Hydropower Energy Generation, Proceedings of the 11th International Conference on Hydroscience \& Engineering, Karlshure-Bundesanstalt für Wasseserbau, 109-118, 2014.

[16] Klipsch T., HEC-ResSim Enhancements: Better Tools to Simulate the Operation of California Reservoirs, Water and Environmental Modeling Forum (CWEMF) Annual Meeting, Sacramento, CA, USA, 2007. 
